\title{
A CONTABILIDADE COMO FERRAMENTA DE GESTÃO PARA PROFISSIONAIS LIBERAIS DE CONSULTÓRIOS MÉDICOS E ODONTÓLOGICOS
}

\section{ARTIGO ORIGINAL}

SILVA, Yan Keisson de Lima da ${ }^{1}$, LIMA, Kamilla Barros de $^{2}$, SILVA, Raquel Trindade ${ }^{3}$, SOUZA, Josiane Duarte de ${ }^{4}$, ROBERTO, José Carlos Alves ${ }^{5}$, SERRA, Meg Rocha da Cunha6 ${ }^{6}$, LOPES, Nelânia Ferreira ${ }^{7}$

SILVA, Yan Keisson de Lima da. Et al. A contabilidade como ferramenta de gestão para profissionais liberais de consultórios médicos e odontológicos. Revista Científica Multidisciplinar Núcleo do Conhecimento. Ano. 06, Ed. 10, Vol. 04, pp. 05-26. Outubro 2021. ISSN: 2448-0959, Link de acesso: https://www.nucleodoconhecimento.com.br/administracao/profissionais-liberais, DOI: 10.32749/nucleodoconhecimento.com.br/administracao/profissionais-liberais

\section{RESUMO}

O meio dos negócios pode ser compreendido como um complexo âmbito de disposições que impactam, a todo momento, na sobrevivência das empresas. Para que os profissionais liberais de consultórios médicos e odontológicos possam garantir o sucesso do seu negócio é essencial que estejam bem assistidos por profissionais contábeis e ferramentas que Ihe proporcionem segurança nas tomadas de decisões. Do contexto de avaliação da organização financeira da entidade,

\footnotetext{
${ }^{1}$ Graduando do Curso de Contabilidade.

${ }^{2}$ Graduando do curso de Contabilidade.

${ }^{3}$ Graduando do Curso de Contabilidade.

${ }^{4}$ Graduanda do curso de Ciências Contábeis

${ }^{5}$ Orientador. Mestre em Engenharia de produção. Especialista Logística empresarial. Graduado em Administração com Ênfase em Marketing.

${ }^{6}$ Orientadora. Mestra em Engenharia de Processos Industriais pela UFPA, especialista em Controladoria e Auditoria Contábil pelo Ciesa, Graduada em Ciências Contábeis pelo Centro Universitário do Norte. Graduada em Ciências Econômicas pelo Centro Universitário do Norte.

${ }^{7}$ Orientadora. Especialista em Auditoria Contábil, Financeira e Tributaria e Graduada em Ciências Contábeis.
}

RC: 98834

Disponível em:

https://www.nucleodoconhecimento.com.br/administracao/profissionais-liberais 
emergiu então, a seguinte questão norteadora: De que forma a contabilidade pode atuar como ferramenta de gestão para profissionais liberais de consultórios médicos e odontológicos? Assim, o objetivo geral deste trabalho é investigar como são utilizadas as ferramentas contábeis gerenciais em empreendimentos de profissionais liberais de consultórios médicos e odontológicos. Para tal, realizou-se uma revisão de literatura, do tipo pesquisa bibliográfica a partir de uma pesquisa descritiva de caráter qualitativo. Assim, por meio desta pesquisa, chegou-se à conclusão de que os consultórios, seja de dentistas ou médicos, precisam de uma estrutura ou sistema que utilize ferramentas pautadas no acompanhamento das operações, estrutura e ambiente organizacional, no campo contábil. Por fim, concluiu-se que as ferramentas da contabilidade para os profissionais liberais de consultórios médicos e odontológicos, em sua gestão, gera uma maior autonomia para cumprir as atividades do dia a dia, tornando estes negócios mais produtivos.

Palavras-chave: Contabilidade, Ferramentas contábeis, Profissional liberal.

\section{INTRODUÇÃO}

O universo dos negócios pode ser compreendido como um complicado meio de disposições que refletem, a todo momento, de forma positiva ou negativa, na saúde das empresas. Contudo, o gestor precisa estar bem assistido por profissionais e amparado por setores que the proporcionem segurança nas tarefas cotidianas de tomadas de decisão.

Dentre estes setores, destaca-se a contabilidade, que provê um grupo de ferramentas que permitem, entre outras, uma visão pormenorizada da situação financeira da organização por meio de informações de relatórios temporais (CREPALDI, 2012). A sua importância é de grandes proporções para os empresários, complementa Marion (2012), que além da imposição legal das disposições financeiras das organizações para o controle estatal, proporciona ferramentas de gestão de modo a obter maior produtividade na utilização de seus ativos.

RC: 98834

Disponível em:

https://www.nucleodoconhecimento.com.br/administracao/profissionais-liberais 
Sabendo-se que as ações de prestação de serviços por profissionais da área médica e odontológica em consultórios têm uma grande representatividade para o setor levar em conta os modelos de gestão que estão sendo seguidos no gerenciamento das atividades relacionadas a essa prestação de serviços, é essencial para assegurar a continuidade e o sucesso do negócio. Neste contexto, ressalta-se que o objeto de análise deste estudo é a contabilidade empresarial voltada para profissionais liberais de consultórios médicos e odontológicos.

Contudo, sabe-se que os profissionais liberais também precisam atentar para a gestão contábil dos seus negócios, pois, por trabalharem de forma independente é necessário que esta atuação seja organizada e que as tributações sejam realizadas de forma adequada, para que não haja problemas com o Fisco.

Desta forma, a problemática deste estudo busca saber: De que forma a contabilidade pode atuar como ferramenta de gestão para profissionais liberais de consultórios médicos e odontológicos?

A fim de responder o problema científico citado acima, o presente artigo tem o objetivo geral de investigar como são utilizadas as ferramentas contábeis gerenciais em empreendimentos de profissionais liberais de consultórios médicos e odontológicos.

De tal modo, realizou-se uma revisão de literatura, do tipo pesquisa bibliográfica, descritiva de caráter qualitativo, fundamentada em publicações, na área de Contabilidade, de dissertações, teses, artigos científicos de periódicos e capítulos de livros disponíveis em bibliotecas de instituições de ensino superior e virtuais, com a finalidade de entender como são utilizadas as ferramentas contábeis gerenciais em empreendimentos de profissionais liberais de consultórios médicos e odontológicos. 


\section{REFERENCIAL TEÓRICO}

De acordo com Lakatos e Marconi (2010), o referencial teórico exige a primeira aproximação do pesquisador com o tema, para familiarizá-lo com os acontecimentos conexos ao problema a ser estudado.

\subsection{CONTABILIDADE}

A Contabilidade apareceu, basicamente, da necessidade de aparelhar os dados patrimoniais, econômicos e financeiros de uma apontada unidade econômica e administrativa, podendo ser uma empresa, o governo ou uma pessoa física, ou seja, uma entidade (DA COSTA et al., 2020).

Neste contexto, várias são as definições de Contabilidade. A Contabilidade Teórica constitui regras e princípios a serem ressaltados pelos contabilistas, com o desígnio de uniformizar procedimentos (PADOVEZE, 2012). Assim, atribui-se à mesma, constantemente, o condão de ciência.

Entretanto, ela não é uma ciência exata como a Matemática, porque a Contabilidade está encravada no campo das ciências sociais, e usa a matemática somente como ferramenta para determinar o valor dos componentes patrimoniais. Antigamente, quando ainda não fixos os princípios que a conduzem, denominavam-na até mesmo de arte. Porém, hoje, ela deve ser entendida, sempre, como ciência (OLIVEIRA et al., 2017).

A Contabilidade é uma Ciência Social com integral fundamentação epistemológica. Por consequência, todas as classificações - método, conjugado de procedimentos, técnica, sistema, arte, para mencionarmos as mais correntes - referem-se a simples enfoques ou aspectos da Contabilidade, habitualmente relativos à sua aplicação prática, na dissolução de questões concretas (MOREIRA et al., 2013).

Em busca de compreender este conceito de Contabilidade, na Tabela 1, tem-se a decomposição da mesma nos seus núcleos verbais, que são: registrar, controlar e

RC: 98834

Disponível em:

https://www.nucleodoconhecimento.com.br/administracao/profissionais-liberais 
orientar. Atribuindo-Ihes a devida função, tem-se a aplicação dos próprios objetivos da Contabilidade. De tal modo, as funções de registro, controle e orientação/ informação são:

Tabela 1: Decomposição dos núcleos da Contabilidade.

\begin{tabular}{|l|l}
\hline Registro & $\begin{array}{l}\text { Para se ter controle e a orientação, os acontecimentos precisam } \\
\text { ser comprovados de alguma forma; o meio empregado em } \\
\text { Contabilidade é o registro destes acontecimentos. O registro se } \\
\text { sintetiza à escrituração dos acontecimentos que sucedem com o } \\
\text { patrimônio de uma entidade. }\end{array}$ \\
\hline Controle & $\begin{array}{l}\text { Tem a importante função diante da necessidade da preservação de } \\
\text { bens e direitos, sobretudo quando se trata de entidades comerciais, } \\
\text { que ficam sempre em disputa para conquista de mercado. Busca-se } \\
\text { ainda o acompanhamento do planejamento, porque não satisfazem } \\
\text { bons planos se, no instante da execução, desconsideram-se todos os } \\
\text { critérios científicos usados no seu desenvolvimento, sendo } \\
\text { indispensável um controle rigoroso para a sua dinâmica efetivação. }\end{array}$ \\
\hline $\begin{array}{l}\text { Através dos relatórios contábeis, é notificada a circunstância da } \\
\text { entidade. Esses relatórios, usados corretamente, serão parâmetros } \\
\text { (orientação) para um criterioso e apropriado planejamento, assim } \\
\text { como para constatar e escoltar do que se planejou está sendo } \\
\text { cumprido, e se as metas delineadas estão sendo alcançadas. Poder- } \\
\text { se-ia afirmar que se tem o coração da Contabilidade, ou seja, os } \\
\text { meios e os fins, já que o fim da Contabilidade é a prestação de } \\
\text { informações favoráveis, e isto será possível apenas mediante } \\
\text { registros e controles constantes, que comprovem as modificações } \\
\text { patrimoniais, tanto as qualitativas quanto as quantitativas. }\end{array}$
\end{tabular}

Fonte: Adaptado de Moreira et al. (2013). 
Portanto, é uma ciência econômico-administrativa que emprega procedimento próprio para registrar, analisar, controlar e comprovar os aspectos referentes ao patrimônio das entidades, com o desígnio de prover dados aos agentes interessados para auxiliar a tomada de decisões.

\subsection{PROFISSIONAL LIBERAL}

O profissional liberal tem formação técnica ou graduação em determinada área, podendo atuar como empregado dentro da Consolidação das Leis do Trabalho (CLT) ou por conta própria, tanto como Pessoa Física, ou como Pessoa Jurídica (RIBEIRO et al., 2019).

De acordo com Ferreira et al. (2020), trata-se do profissional de nível técnico ou universitário, que possui registro em uma ordem ou conselho profissional, em que se pode compor uma empresa ou ser funcionário desta.

Esses profissionais são registrados nos conselhos de classe ou ordens, como o Conselho Regional de Medicina (CRM), Conselho Federal de Odontologia (CFO) ou a Ordem dos Advogados do Brasil (OAB). Esses conselhos determinam os processos éticos e técnicos da profissão, sendo que somente profissionais registrados podem desempenhar essas profissões.

O profissional liberal age em atividades intelectuais e pode responder cível e criminalmente por seu trabalho, partindo daí a precisão do registro. Contudo há atividades que são consideradas liberais e têm sua própria legislação (FERREIRA et al., 2020).

\subsubsection{MÉDICOS}

As doenças físicas ou psicológicas seguem a humanidade desde sua ascendência, e a procura pelas formas de cura também. E assim, com o descobrimento das formas de curar apareceu a responsabilização dos operantes dessas formas, como o médico (BYNUM, 2011).

RC: 98834

Disponível em:

https://www.nucleodoconhecimento.com.br/administracao/profissionais-liberais 
Neste contexto, diversos são os profissionais liberais que prestam serviços, e entre eles tem-se a profissão da medicina, que atuando na condição de profissional liberal, vende seus serviços, contratando absolutamente com o paciente, fornecendo seus serviços. Assim, com isso o médico vem cumprindo a sua profissão de maneira liberal desde os tempos mais distantes de nossa vida (MACIEL et al., 2010).

Sabe-se que desta forma, o médico como profissional liberal presta seus serviços de forma independente, ou seja, o cliente não diz ao médico como desenvolver a operação em que foram especializados.

\subsubsection{DENTISTAS}

O dentista é o profissional direcionado para a precaução e a terapêutica das problemáticas bocais, compreendendo dentes, gengivas, ossos do rosto, bochechas, lábios e língua, promovendo a saúde do homem na sua integralidade, em concordância com o meio ambiente (PEREIRA, 2012).

Segundo Silva et al. (2017), uma das grandes dificuldades deparadas pelo dentista é a gestão operacional de seu consultório. Ele como profissional liberal deve multiplicar suas capacidades para agir em diversos segmentos juntamente com sua profissão. Assim sendo, a atuação do dentista como gestor da sua empresa é de grande relevância para a adequada performance financeira de seu consultório.

\subsection{CONTABILIDADE PARA MICROEMPRESAS}

A categorização de empresa como Microempresa (ME) está relacionada a finalidade de cada órgão governamental, pois não existe um parâmetro exclusivo para determinar a definição de MEs (LEMES JÚNIOR; PISA, 2010). Desta forma, utilizase como fundamento, o parâmetro do Sebrae, da Receita Federal do Brasil (RFB), do Banco Nacional de Desenvolvimento Econômico e Social (BNDES), e outros, visto na Tabela 2.

RC: 98834

Disponível em:

https://www.nucleodoconhecimento.com.br/administracao/profissionais-liberais 
Tabela 2: Estratificação das Micro e pequenas empresas.

\begin{tabular}{c|c|c|c}
\hline \multirow{2}{*}{ Entidade } & Segmento & Microempresa & Empresa de Pequeno Porte \\
\hline \multirow{2}{*}{ SEBRAE } & Indústria e construção civil & Até 19 empregados & De 20 à 99 empregados \\
\cline { 2 - 4 } & Comércio e serviços & Até 09 empregados & De 10 à 49 empregados \\
\hline RFB & Indústria, comércio e serviços & Até R\$ 360.000 & $\begin{array}{c}\text { De R } 360.000 \text { até R\$ } \\
3.600 .000\end{array}$ \\
\hline BNDES & Indústria, comércio e serviços & Até RS 2,4 milhões & $\begin{array}{c}\text { Acima de } R S 2,4 \text { milhões até } \\
\text { R } \$ 16 \text { milhões }\end{array}$ \\
\hline
\end{tabular}

Fonte: Stacke, 2017.

O uso do conhecimento contábil, como instrumento de suporte ao controle e tomada de decisão, acontece diante do grau de necessidade do gestor ou proprietário (CREPALDI, 2012). Segundo Ludicibus (2010), o acesso os conhecimentos contábeis, por parte do microempresário é essencial para que ele consiga desempenhar suas ações e desenvolver as melhores determinações, para que se possa ter o correto planejamento e controle das atividades.

De tal modo, a contabilidade é útil para os diversos níveis de atividade empresarial, colaborando para o acompanhamento das ações como vendas, estoques, receitas, despesas e custos, e outros (LEMES JÚNIOR; PISA, 2010).

Assim, a administração de microempresas pode ser feita através de controles de contas a pagar, contas a receber, de saldos bancários e de caixa e administração de estoques, e outros, que são vistos como simples e práticos, assim, pode-se ter o domínio e informações dos vencimentos, sendo possível determinar as prioridades de pagamento, se for necessário, a organização do fluxo de caixa que ajuda a identificar o capital de giro, prever o montante preciso de compras, melhorando o investimento em estoques, manter o registro diário de recebimentos e pagamentos, possibilitando comparar as entradas em relação as vendas e outros recebimentos, com as saídas relacionadas aos pagamentos (SOUZA; RIOS, 2011). 


\subsubsection{PARA PROFISSIONAIS LIBERAIS}

Quando um profissional opera como CLT, o empregador responsabiliza-se pela recolhida dos tributos. O profissional liberal, assim, responde por esses comprometimentos. Isso constitui arcar com o Imposto de Renda de Pessoa Física ou Jurídica, Instituto Nacional do Seguro Social (INSS), Imposto Sobre Serviços (ISS) e Programa de Integração Social (PIS) (BARBOSA, 2017).

Considera-se ainda que os serviços prestados necessitam ser corretamente contabilizados e delineados na declaração do Imposto de Renda. Assim, impede-se prejuízos com multas. (BARBOSA, 2017).

Os tributos variam conforme a maneira com que o profissional desempenha sua atividade profissional. Os profissionais liberais podem operar como Pessoas Físicas ou Pessoas Jurídicas, sendo que cada maneira de ação tem pontos positivos e negativos. Neste contexto, o contador para profissionais liberais deve ajudar no entendimento da melhor maneira de desempenho.

A contabilidade para profissionais liberais age na administração dos tributos e na administração financeira, ajudando ainda na administração dos dados a respeito da atividade desempenhada, o mercado, os clientes e a concorrência (FERREIRA et al., 2020). Ainda determina demonstrativos com dados da performance profissional, ajudando o profissional decidir grandes escolhas e investir na ampliação de sua carreira.

\subsubsection{FERRAMENTAS CONTÁBEIS}

A contabilidade gerencial se intensifica dentro das empresas, como uma ferramenta que ajuda os usuários nas necessitadas tomadas de decisões, usando os vários relatórios, por ela, provocados e emitidos, como: Demonstração do Resultado do Exercício, Balanço Patrimonial, Fluxo de Caixa, dentre outros (FERREIRA et al., 2020), explicados a seguir.

RC: 98834

Disponível em:

https://www.nucleodoconhecimento.com.br/administracao/profissionais-liberais 


\subsubsection{BALANÇO PATRIMONIAL - BP}

De acordo com Szuster et al. (2011), a ferramenta balanço patrimonial tem a finalidade de exibir a disposição financeira da organização em um apontado instante, assim como apresentar a capacidade da entidade em originar fluxos de caixa. Este precisa ser aprontado ao final de cada ano, e expor de maneira sistemática, os ativos (bens e direitos), passivos (obrigações) e patrimônio líquido (diferença entre os ativos e passivos) de uma organização.

Para Ching et al. (2010), o balanço, em uma determinada data, apresenta a posição financeira empresarial, tendo à esquerda os ativos (recursos de propriedade da organização) e à direita o passivo (obrigações que a organização tem com terceiros) e o Patrimônio Líquido (PL) (capital próprio da organização), como pode ser visto no Modelo de Quadro 3, a seguir.

Quadro 1: Modelo de Balanço patrimonial

BALANÇO PATRIMONIAL - 200X

\begin{tabular}{|c|c|}
\hline ATIVO & PASSIVO \\
\hline $\begin{array}{l}\text { Disponível...................................................... } \\
00\end{array}$ & $\begin{array}{l}\text { Empréstimos } \\
\text { financiamentos........................39. } \\
200\end{array}$ \\
\hline $\begin{array}{l}\text { Duplicatas } \\
\text { receber................................172.480 }\end{array}$ & 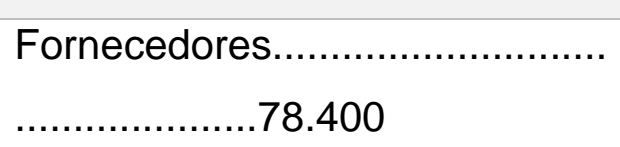 \\
\hline 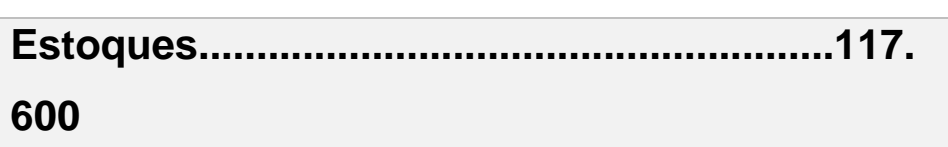 & $\begin{array}{ll}\text { Obrigações } & \text { fiscais } \quad \mathrm{e} \\
\text { previden........................23.520 }\end{array}$ \\
\hline $\begin{array}{ll}\text { Outros } & \text { valores } \\
\text { receber..........................62.720 }\end{array}$ & $\begin{array}{l}\text { Obrigações } \\
\text { trabalhistas....... } \\
.39 .200\end{array}$ \\
\hline 392.000 & 235.200 \\
\hline
\end{tabular}




\begin{tabular}{|c|c|}
\hline REALIZÁVEL A LONGO PRAZO & EXIGÍVEL A LONGO PRAZO \\
\hline $\begin{array}{l}\text { Créditos } \\
\text { diversos.........................................7.840 }\end{array}$ & $\begin{array}{l}\text { Empréstimos } \\
\text { financiamentos....................156. } \\
800\end{array}$ \\
\hline 7.840 & 392.000 \\
\hline PERMANENTE & CAPITAL DE TERCEIROS \\
\hline Investimento & \\
\hline $\begin{array}{lll}\text { Participação em outras empresas } \\
\ldots \ldots \ldots \ldots . . . .15 .680\end{array}$ & \\
\hline $\begin{array}{cccc}\text { Terrenos } & \text { para } & \text { futura } & \text { utilização } \\
\ldots \ldots \ldots \ldots \ldots \ldots . . .235 .200 & & \end{array}$ & \\
\hline 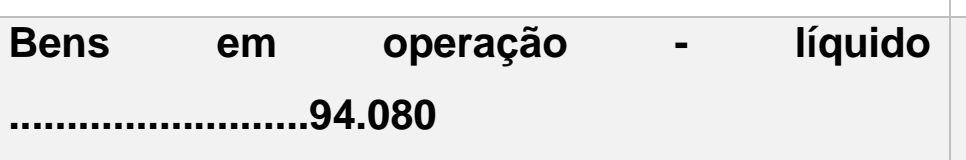 & PATRIMONIO LIQUÍDO \\
\hline $\begin{array}{l}\text { Imbolização } \\
\text { andamento...........................15.680 }\end{array}$ & $\begin{array}{l}\text { Capital } \\
\text { social.................................. } \\
\ldots . .313 .600\end{array}$ \\
\hline 109.760 & $\begin{array}{l}\text { Reserva } \\
\text { lucros................................... } \\
. .23 .530\end{array}$ \\
\hline & $\begin{array}{lrr}\text { Lucros } & \text { ou } & \text { prejuízos } \\
\text { acumulados....................54.880 }\end{array}$ \\
\hline $\begin{array}{ll}\text { Despesas } & \text { pré- } \\
\text { operacionais.............................23.520 }\end{array}$ & 392.000 \\
\hline $\begin{array}{ll}\text { Total } & \text { do } \\
\text { permanente................................384.160 }\end{array}$ & \\
\hline 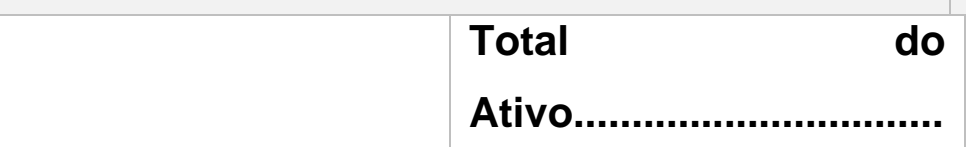 & $\begin{array}{c}\text { Total do Passivo }+ \text { PL } \\
\ldots \ldots \ldots \ldots \ldots \ldots \ldots \ldots .784 .000\end{array}$ \\
\hline
\end{tabular}

RC: 98834

Disponível em:

https://www.nucleodoconhecimento.com.br/administracao/profissionais-liberais 
Fonte: Duarte, 2015.

Tem-se acima um modelo de balanço patrimonial, a fim de refletir a posição financeira em apontado momento da empresa.

\subsubsection{DEMONSTRAÇÃO DO RESULTADO DO EXERCÍCIO - DRE}

Conforme Marion (2012), cada exercício possui duração anual, onde é verificado o resultado do período. No fim de cada período, a totalidade das despesas e receitas precisam ser transferidas para demonstração do resultado do exercício. Destaca-se que não pode empilhar despesas e receitas de um ano para o outro, principiando a escrituração do zero no exercício seguinte.

De acordo com Ludicibus (2010), trata-se de uma síntese das receitas e despesas em um tempo de 1 ano, diferenciando-se na situação de pequenas e médias empresas, devendo comprovar as despesas deduzidas das receitas, verificando-se o lucro, sem ressaltar os setores básicos de despesas.

Para Basso (2011 p. 306):

Concebida para demonstrar a formação do resultado final do exercício, ou seja, o lucro ou o prejuízo, a DRE está estruturada de forma a evidenciar as diversas fases do resultado, iniciando com o valor da receita operacional bruta apurada nas operações de vendas e de prestações de serviços da entidade, passando pela dedução dos encargos tributários, devoluções e abatimentos a ela relativos, bem como dos seus respectivos custos, apurando-se o lucro operacional bruto.

Conforme o princípio da competência, ratifica-se a concepção do resultado do exercício na comparação entre as receitas e os pertinentes custos e despesas. Ressalta-se que esta apresentação precisa ser exposta verticalmente, discriminando-se seus elementos de maneira sumarizada (SANTOS; SCHMIDT, 2011).

RC: 98834

Disponível em:

https://www.nucleodoconhecimento.com.br/administracao/profissionais-liberais 
Um modelo de DRE pode ser visto na Figura 1.

Figura 1: Modelo de DRE.

\begin{tabular}{|c|c|}
\hline \multicolumn{2}{|c|}{ Demonstração do Resultado do Exercício - DRE } \\
\hline \multicolumn{2}{|c|}{ Período: 2/Ano1 } \\
\hline \multicolumn{2}{|c|}{ Empresa: $X \times X \times X$ Comércio Ltda. } \\
\hline ( + ) Receita de Vendas & $3.300,00$ \\
\hline$(+)$ Outras Receitas & 400,00 \\
\hline$(=)$ Total de Receita & $3.700,00$ \\
\hline ( - ) Custo da Mercadoria & $(2.050 .00)$ \\
\hline ( - ) Custo Financeiro & $(150,00)$ \\
\hline ( - ) Impostos & $(300,00)$ \\
\hline$(=)$ Total das Despesas & $(2.500,00)$ \\
\hline ( = ) Lucro do Exercício & $1.200,00$ \\
\hline
\end{tabular}

Fonte: CEMIN et al., 2014.

\subsection{CONTABILIDADE DE CUSTOS}

Para entender quais os custos em uma empresa, primeiramente deve-se saber a diferença entre gastos e despesas. Para Padoveze (2012), gasto é um sacrifício financeiro, que representado pela entrega e promessa de entrega de ativos, pela obtenção de qualquer bem ou serviço. Entretanto, esses gastos foram classificados por Ribeiro et al. (2019), quanto aos seus aspectos econômicos, em gasto de investimento e gasto de consumo, sendo que ambos podem dar origem a um custo e/ou a uma despesa, de acordo com sua destinação.

Custo é um gasto referente à bem ou serviço aproveitado na produção, enquanto despesa refere-se a um bem ou serviço consumido direta ou indiretamente para o alcance de receitas (SANTOS, 2009).

Segundo Santos (2009), a relação da contabilidade com os custos surgiu com as indústrias, quando o contador, habituado às empresas comerciais, deparou-se com o valor de compras sendo substituído por uma série de valores pagos pelos fatores de produção, utilizados na confecção dos produtos.

RC: 98834

Disponível em:

https://www.nucleodoconhecimento.com.br/administracao/profissionais-liberais 
A contabilidade de custo tem por objetivo produzir informações para auxiliar a contabilidade financeira e a gerencial. Esta evoluiu muito e passou a ser importante no controle e decisões gerenciais, para isso necessitou-se criar várias classificações que auxiliassem o seu uso (SZUSTER, 2011).

\subsubsection{CONTROLE DE CUSTOS}

O controle de custo é usado com 3 finalidades: nortear as decisões que viabilizem a análise e escolha da melhor opção entre as exibidas; analisar o efeito das decisões tomadas diante dos objetivos delineados e nortear as ações corretivas. E neste contexto, o custo-meta e o custo-padrão, especificamente métodos de projeto e controle de custos, estão entrelaçados com 0 atendimento das três finalidades (SANTOS, 2009).

O sistema de custo-padrão tem se destacado entre pesquisadores e profissionais do setor custos. O custo-padrão é o custo, de forma científica, predelineado para a geração de uma unidade, ou de um quantitativo "x" de unidades do produto, em um período característico no futuro imediato. Este custo é desenvolvido segundo definições de engenharia, metrologia e outras ciências exatas, levando em considerando ainda as definições administrativas, contábeis, econômicas, psicológicas etc. $\mathrm{O}$ grande benefício é gerar estímulo desde que os participadores ajam com a máxima eficiência admissível buscando obter ou até exceder os objetivos constituídos (HOJl, 2017).

Quanto ao custo-meta, trata-se de um artifício de ajuda ao desenvolvimento de produtos lucrativos, sendo uma maneira de planejamento de custo norteado pelo mercado. Assim, para garantir a sobrevivência das empresas, deve-se ter a capacidade de elaborar produtos que levem a qualidade e funcionalidade que os clientes anseiam, ao preço que eles esperam pagar e que, ao mesmo tempo, produzam o lucro ambicionado pela organização. Desta forma, trata-se de uma metodologia de gerenciamento do lucro, assim não é somente um sistema de 
controle de custos, mas um vasto enfoque da gestão do custo e do lucro (GITMAN, 2010).

\subsubsection{CONTROLE DE DESPESAS}

O controle de despesas atua para se ter uma cautela do que se deve para pagar no decorrer de um mês, fazendo com que a organização siga o seu progresso ou não. $\mathrm{Na}$ contabilização dos produtos finais, ele atua para registrar o valor de cada despesa que deve ser adicionada para se alcançar o lucro almejado da entidade, pois se sabe que os controles são essenciais em um processo empresarial (HOJl, 2017).

\subsection{CONTROLE FINANCEIRO}

De acordo com Sanvicente e Santos (2013), controlar significa seguir o cumprimento das ações uma forma a mais rápida que puder, e conferir o comportamento real com o desenhado. Esta função abrange a origem de informações para a tomada de decisões de análise e ocasional conveniência do desempenho obtido.

De tal modo, o controle financeiro abrange o método de acompanhamento e checagem de performance do setor financeiro de uma entidade. Assim, este tipo de controle auxilia o profissional a constatar se está obtendo lucro ou não, se está havendo muitos gastos ou não, e se os fins determinados estão sendo obtidos, conforme o projetado.

Para Lacombe (2009), controle é o papel administrativo que incide em avaliar e retificar o comportamento de subordinados para garantir que os desígnios e as intenções da organização sejam alcançados e os planos estabelecidos para atingilos sejam desenvolvidos". Assim, percebe-se que planejamento e controle são papeis iguais da administração, já que não vale planejar se não existir controle, e não se pode controlar se não existir planejamento (OLIVEIRA, 2013).

$\mathrm{RC}: 98834$

Disponível em:

https://www.nucleodoconhecimento.com.br/administracao/profissionais-liberais 
Verifica-se que o controle financeiro está atrelado ao planejamento financeiro, uma vez que o controle permite analisar se os planos estão sendo desenvolvidos da forma apropriada e ocasionando os efeitos prometidos.

\subsubsection{FLUXO DE CAIXA}

Segundo Marion (2012), o fluxo de caixa é definido pelo relatório a partir do qual se alcança as entradas e saídas de caixa. A partir dele, a organização estará apta para averiguar os pagamentos por apontado período, constatando se existe possibilidade de investimentos, e analisando a melhor época para ser possível fazer o planejamento de apontada compra. Assim, trata-se de um norte para empresa nas tomadas de decisão.

Segundo Padoveze (2012), o fluxo de caixa pode abranger o período que a gestão achar necessário, desta maneira, os habituais estão relacionados ao diário ou mensal. A divisão em segmentos do Fluxo de Caixa acontece em três grandes áreas: I - atividades operacionais, II - atividades de investimento e III - atividades de financiamento. Esta armação refere-se as considerações fundamentais dos relatórios contábeis (BP e a DRE), entretanto destaca-se, que nas MPEs, esse instrumento pode ser simples e adaptado à precisão da organização (LIMA e SOUSA, 2013).

No quadro 2, pode-se ver um modelo de Fluxo de Caixa.

Quadro 2: Modelo de Fluxo de caixa.

\begin{tabular}{|l|l|l|l|l|l|}
\hline & \multicolumn{3}{|c|}{ SEMANA 1 } & \multicolumn{2}{l|}{ SEMANA 2 } \\
\hline E & - & PREVISTO & REALIZADO & PREVISTO & REALIZADO \\
\hline N & SALDO INICIAL & 10000 & $\mathbf{1 1 0 0 0}$ & $\mathbf{1 2 4 2 0}$ & $\mathbf{1 1 5 8 0}$ \\
\hline T & Vendas á vista & 8000 & 7000 & 8000 & 7580 \\
\hline R & Cheque pré & 2500 & 2000 & 8000 & 9000 \\
\hline A & A receber & 4500 & 5000 & 6500 & 5000 \\
\hline
\end{tabular}

RC: 98834

Disponível em:

https://www.nucleodoconhecimento.com.br/administracao/profissionais-liberais 


\begin{tabular}{|c|c|c|c|c|c|}
\hline D & Outros & 900 & 900 & 620 & 570 \\
\hline \multirow[t]{3}{*}{ A } & TOTAL ENTRADA & 15900 & 14900 & 23120 & 22150 \\
\hline & Fornecedores & 1200 & 900 & 950 & 1050 \\
\hline & Água e luz & 280 & 320 & 300 & 260 \\
\hline$S$ & Telefone e Net & 450 & 550 & 450 & 350 \\
\hline A & Combustível & 450 & 300 & 400 & 320 \\
\hline í & Taxas bancárias & 80 & 120 & 80 & 110 \\
\hline D & Materiais Consumo & 200 & 280 & 200 & 120 \\
\hline \multirow[t]{8}{*}{$A$} & Compra Equipamento & 1200 & 1800 & 250 & 900 \\
\hline & Pró-Labore & 4000 & 4000 & 0 & 1200 \\
\hline & Impostos e taxas & 4500 & 4500 & 200 & 200 \\
\hline & Aluguel e cond & 1000 & 1000 & 0 & 0 \\
\hline & Outras despesas & 120 & 550 & 120 & 400 \\
\hline & TOTAL DE SAIDA & 13480 & 14320 & 2950 & 4910 \\
\hline & $\begin{array}{l}\underline{\text { SALDO }} \\
\text { OPERACIONAL }\end{array}$ & 2420 & 580 & 20170 & 17240 \\
\hline & SALDO FINAL & 12420 & 11580 & 32590 & 28820 \\
\hline
\end{tabular}

Fonte: SILLA, 2010.

\subsubsection{CONTROLE BANCÁRIO}

O controle bancário em uma empresa precisa ser cotidiano e realizar o registro de todas as movimentações. Este controle tem o intuito de conferir os lançamentos da organização e os registros efetivados pelo banco. Assim, pode-se identificar contestações de registros, caso aconteça, e ainda pode gerar informações a respeito de saldos bancários existentes, assim como identificar se os saldos são satisfatórios para honrar com os comprometimentos do dia (ROSS et al., 2010)

Ou seja, trata-se dos depósitos e créditos feitos conta da organização, assim como todos os pagamentos realizados através de sistemas bancários e outros valores 
debitados em conta, como tarifas bancárias, juros acerca de saldo devedor, faturas de energia, de água e telefone e outras.

\subsubsection{CONTROLE DE RECEITAS}

A receita é a comercialização de produtos, mercadorias ou de serviços. Trata-se da entrada de itens para o ativo na forma de dinheiro ou de direitos a receber, apropriado normalmente à venda de bens ou serviços (LACOMBE, 2009). Venda de produtos pode ser concretizada: à vista $\rightarrow$ com a entrada de dinheiro no caixa, na mesma forma do ato da entrega do bem ou serviço ao cliente. Por isso, não existe venda à vista com 7 dias de prazo para pagamento, como foi determinado pelo comercio atual. A prazo $\rightarrow$ com a entrada do dinheiro que ocorrerá no futuro (podendo ser efetuado em apenas $1 \mathrm{dia}$ ) (ROSS, 2010).

Faz se necessário que no momento da entrega da mercadoria ou ocorrência do serviço que gera, então, um direito de recebimento conhecido como contas a receber. As receitas elevam o ativo, visto que o valor que havia no estoque é vendido por um valor maior do que o registrado, sendo que o estoque é registrado pelo valor de compra ou de custo e a receita é validada pelo valor de efetivação ou pelo preço do produto ou serviço, (SANVICENTE e SANTOS, 2013).

Assim, o controle de receitas é responsável por realizar os registros do cotidiano, que atuam como fundamento para o controle de receita e despesas da empresa, apuração de impostos e outras exigências fiscais (VERGARA, 2013). Destaca-se que o profissional determinado para esta função precisa estar sempre atualizado das alterações da legislação.

\subsection{ORÇAMENTO}

Segundo Padoveze (2012), trata-se de uma ferramenta de controle de excelência voltado ao processo operacional da organização, já que abrange todos os grupos da empresa. Assim, é um plano de ação que auxilia na composição e prática de um 
plano, conferindo dados constantes do sistema de informação contábil de agora, adicionando dados antevistos para o exercício seguinte, com suas carecidas mudanças.

O orçamento empresarial é empregado principalmente para solucionar problemas gerenciais, como no caso da determinação das metas (CARRARO et al., 2018).

Segundo Padoveze (2012), os desígnios do orçamento empresarial são:

1. orçamento como sistema de autorização;

2. instrumento para projeções e planejamentos;

3. meio de diálogo e coordenação;

4. ferramenta de motivação;

5. ferramenta de análise e controle;

6. fonte de dados e informações para tomada de decisão.

Seu uso é vantajoso por fazer com que os gestores pensem e delineiem quanto ao futuro da organização, impactando nas atividades em geral, cogitando vendas, despesas e investimentos, reorganizando de tal modo as atividades com o intuito de obter a projeção considerada no orçamento, abrangendo todos os setores da empresa (LIMA; SOUSA, 2013).

Assim, o orçamento precisa juntar os múltiplos objetivos da entidade, na busca da expressão do plano e controle de resultados. Deste modo, o plano orçamentário não é somente prever o que vai ocorrer e seu futuro controle, mas ainda constituir e dispor objetivos para todos os setores da empresa, de maneira que todos os colaboradores trabalhem sinergicamente na busca de desenvolver planos de lucros. 


\subsection{GESTÃo CONTÁBIL PARA CONSULTÓRIO MÉdICO E ODONTOLÓGICO}

A gestão abrange ações como planejar, analisar e controlar as atividades financeiras, englobando despesas (fixas e variáveis), lucro, empréstimos, melhorias e tudo que envolva as finanças do consultório.

Segundo Marion (2012), a maioria das informações necessárias ao gestor encontrase conferidas nas notações contábeis, dia a dia, mês a mês e ano a ano, dentro de métodos próprios e dinâmicos que o profissional da contabilidade emprega.

A importância da contabilidade gerencial é de grandes proporções para os empresários, complementa Marion (2012), que além da imposição legal das disposições financeiras das empresas para o controle estatal, fornece ferramentas de gestão de forma a alcançar maior produtividade no emprego de seus ativos.

E neste contexto, destaca-se que conseguir manter a clínica ou consultório abertos exige ter uma boa gestão financeira, mediante profissional de contabilidade especializado, para que não se entre nas estatísticas que apontam que $60 \%$ dos negócios fecham antes de concluir 5 anos (CONDUTTA et al., 2018).

Destaca-se que poucos proprietários e administradores de consultórios utilizam o planejamento tributário como ferramenta de gestão e aperfeiçoamento do desempenho empresarial, deixando de lado muitos benefícios.

Este planejamento é definido como o emprego de várias técnicas previstas na legislação tributária para diminuir a carga tributária e impedir erros que são qualificados como ilícitos fiscais, gerando economia e originando o crescimento da empresa (CREPALDI, 2017).

$\mathrm{Na}$ situação dos consultórios, a escolha do planejamento tributário é ainda mais importante por haver formas de reduzir os impostos para setores da saúde, contudo isso não é do conhecimento de todos.

RC: 98834

Disponível em:

https://www.nucleodoconhecimento.com.br/administracao/profissionais-liberais 
O dentista e o médico recém-formado têm a responsabilidade de exercer sua profissão com excelência, e em muitos casos, optam por abrir o próprio negócio, porém esta é uma tarefa que exige muita atenção e planejamento. De acordo com a história e, conforme o levantamento de dados do IBGE, mais da metade das empresas pagam os seus tributos de maneira incorreta, ocasionando perda de lucratividade e, assim, perda de investimentos para o consultório.

Sabendo-se que o Brasil é um dos países com maior complicação para as entidades apararem seus tributos, e assim, é essencial que haja um auxílio junto a gestão, de profissionais especializados de contabilidade, para que seja feito o recolhimento correto dos tributos impostos pelo Governos Federal e Municipal (MOREIRA et al., 2020).

Destaca-se que os tributos (impostos, taxas e contribuições) são uma grande parcela dos custos para os consultórios, desta forma, para a área da saúde é essencial que se avalie a atividade de forma profunda. Pois, o planejamento de tributos precisa sempre levar em conta o total dos impostos e taxas incidentes na ação do consultório, de maneira a optar pelo melhor regime tributário, a possível equiparação a ações passíveis de diminuição, e ainda das múltiplas vantagens fiscais indicadas pela Legislação Tributária brasileira.

A grande maioria dos dentistas e médicos tem um consultório particular e, como pessoa física, emitem recibos das prestações de seus serviços aos seus clientes. A renda destes profissionais é tributada de acordo com as alíquotas do Imposto de Renda Pessoa Física que varia entre 7,50\% e 27,50\% (CASTRO; BUGARIN, 2017).

Estes profissionais podem escolher abrir uma empresa ou permanecer agindo de maneira autônoma, dependendo da análise do caso, para se alcançar o melhor regime de tributação.

Os profissionais no caso dos médicos ou dentistas que atuam como "autônomo", devem desenvolver alguns métodos para continuar em dia com seus comprometimentos fiscais. De tal modo, levando em conta que, quanto ao Imposto

RC: 98834

Disponível em:

https://www.nucleodoconhecimento.com.br/administracao/profissionais-liberais 
de Renda será tributado conforme a tabela de Imposto de Renda Pessoa Física, que pode variar de isento a $27,5 \%$, e o obrigado a recolher o INSS no percentual de $20 \%$ sobre o ganho mensal, o método menos dispendioso é o desenvolvimento do livro caixa. Assim, o contador coloca todas as despesas dedutíveis no livro caixa para reduzir o lucro tributável (SILVA; MIRANDA, 2019).

Ressalta-se que o dentista e médico com seu consultório que não escritura o livro caixa, apura o IRPF e o INSS pelo valor total bruto de seu rendimento, enquanto o profissional que escritura o livro caixa, apura esses tributos pelo valor líquido do rendimento, assim, rendimento total bruto exceto despesas dedutíveis (SILVA; MIRANDA, 2019).

Enquanto a tributação do dentista e médico, na abertura de uma pessoa jurídica, há os 3 tipos de regimes já citados: Lucro Real, Simples Nacional e Lucro Presumido.

O Regime do Lucro Presumido, que é indicado para empresas com faturamento de no máximo $R \$ 78$ milhões anual é uma boa escolha para consultórios médicos e odontológicos, principalmente se se busca a equiparação a serviços hospitalares, para fins tributários (SILVA; MIRANDA, 2019).

Par que se possa se aceder ao regime do Lucro Presumido, a empresa precisa faturar até $R \$ 78$ milhões, e não agir em apontados ramos. Assim, os serviços odontológicos e médicos são compreendidos, fazendo deste regime uma alternativa. Este não depende efetivamente do custo da folha de pagamento e nem da carga tributária muda entre 13,33 e 16,33\% abarcando PIS/COFINS/IRPJ/CSLL e ISS. O grande diferencial deste regime é que este percentual (13,33 ou 16,33\%) incide sobre a base de cálculo do Lucro presumido (SANTOS et al., 2021).

Já o Simples Nacional, que é o regime que pretende ajudar na tributação para micro e pequenas empresas, que faturam até $R \$ 4,8$ milhões por ano, visto que esta opção depende da folha de pagamento e do faturamento anual. As atividades neste regime são distribuídas por anexos, e, hoje em dia a atividade de odontologia é emoldurada no anexo III, com alíquota inicial de $6 \%$, desde que o custo com a folha,

RC: 98834

Disponível em:

https://www.nucleodoconhecimento.com.br/administracao/profissionais-liberais 
abrangendo o Pró-labore, seja superior a $28 \%$, em caso negativo, será tributado pelo Anexo $\mathrm{V}$, cuja alíquota inicial é de $15 \%$, assim como é qualificada as atividades médicas (SANTOS; VAGO, 2019).

O Lucro Presumido na tributação de consultório médico é a melhor alternativa para faturamento acima de 30 mil reais, onde o ISS pode ser recolhido como sociedade uniprofissional. Destaca-se que a tributação federal pelo lucro presumido para consultórios médicos é de 11,33\% (MOTTA, 2017).

A alternativa do Lucro Real é melhor conferida quanto ao lucro efetivo (receitas menos despesas) é menor que $32 \%$ do faturamento do período abordado, podendo assim ser apurado trimestral ou anualmente. Onde a alíquota do tributo já para cálculo do IRPJ é $15 \%$ para Lucro até $R \$ 20.000,00 /$ mês; $25 \%$ para lucro acima de $R \$ 20.000,00$. Para a CSLL, que é de $9 \%$ sobre qualquer lucro obtido. De tal modo, tem-se $24 \%$ ou $34 \%$ de IRPJ e CSLL aplicados apenas sobre o Lucro obtido. Sendo que se a empresa não apresenta lucros, estes impostos não são recolhidos. Depois, se aplica a alíquota de $1,65 \%$ de PIS e $7,6 \%$ de COFINS sobre a Receita. E finalmente, aplica-se a alíquota de $3 \%$ a $5 \%$ de prestação de serviços (SANTOS; VAGO, 2019).

De tal forma, verifica-se que o regime do Lucro Real não é a melhor opção para o empresário médico e dentista, porém depende de uma análise de cada caso, junto ao contador.

\section{CONSIDERAÇÕES FINAIS}

O objetivo geral deste artigo foi investigar como são utilizadas as ferramentas contábeis gerenciais em empreendimentos de profissionais liberais de consultórios médicos e odontológicos e diante do apresentado, percebe-se que sua finalidade foi alcançada, pois foi possível expor como a contabilidade pode contribuir para que dentistas e médicos mensurem os custos dos processos de seus consultórios. Notando-se assim a grande relevância deste estudo uma vez que a temática 
abordada possui muita colaboração para o progresso da atividade profissional destes profissionais.

Assim, por meio desta pesquisa, chegou-se à conclusão de que os consultórios, seja de dentistas ou médicos, precisam de uma estrutura ou sistema que utilize ferramentas pautadas no acompanhamento das operações, estrutura e ambiente organizacional, no campo contábil.

De tal modo, é essencial o planejamento das atividades a partir das informações contábeis, sendo possível assim ter o domínio e informações dos vencimentos, determinar as prioridades de pagamento, se for necessário, a organização do fluxo de caixa que ajuda a identificar o capital de giro, prever o montante preciso de compras, melhorando o investimento em estoques, manter o registro diário de recebimentos e pagamentos, possibilitando comparar as entradas em relação as vendas e outros recebimentos, com as saídas relacionadas aos pagamentos.

Assim, pode-se captar as necessidades do mercado competitivo e entender a a importância da contabilidade como ferramenta de gestão empresarial.

Verificou-se que o processo de estruturação adequada nas microempresas permite que os gestores tenham uma melhor visão do negócio como um todo, a partir da contribuição das ferramentas da contabilidade em sua gestão, que acaba acarretando uma maior autonomia para cumprir as atividades do dia a dia, tornando estes negócios mais produtivos.

Por fim, este estudo serve de suporte para a conscientização dos profissionais liberais na profissão de médicos e dentistas, como tratados neste estudo, tanto quanto à importância dos conhecimentos característicos referentes à própria gestão de custos como ainda sua aplicação, objetivando proporcionar melhorias na obtenção dos resultados e gerando, portanto, maiores ganhos, quando se tem o suporte de profissionais especializados de contabilidade na gestão da empresa.

$\mathrm{RC}: 98834$

Disponível em:

https://www.nucleodoconhecimento.com.br/administracao/profissionais-liberais 


\section{REFERÊNCIAS}

BARBOSA, F. N. O seguro de responsabilidade civil do profissional liberal: desenvolvimento e atualidades. Pensar-Revista de Ciências Jurídicas, v. 22, n. 1, p. 170-208, 2017.

BASSO, I. P. Contabilidade geral básica. 4. ed. ljuí: Ed. Unijuí, 2011.

BYNUM, W. História da medicina. Souto Maior F, tradutora. Porto Alegre: L\&PM, 2011.

CARRARO, W. B. W. H. et al. Destaques da contabilidade gerencial. Coordenado pelo SEAD/UFRGS. Porto Alegre: Editora da UFRGS, 2018.

CASTRO, F. A. de; BUGARIN, M. S. A progressividade do imposto de renda da pessoa física no Brasil. Estudos Econômicos (São Paulo), v. 47, p. 259-293, 2017.

CEMIN, V. L.; et al. Demonstrações do resultado do exercício-DRE. JOTEC, SP. 2014.

CHING, H. Y.; et al. Contabilidade e finanças: para não especialistas. 3. ed. São Paulo, Pearson Prentice Hall, 2010.

CONDUTTA, L. F.; et al. A gestão da informação contábil-financeira atuando como suporte ao processo decisório: estudo de caso em uma instituição de ensino superior do terceiro setor. XIX ENCONTRO NACIONAL DE PESQUISA EM CIÊNCIA DA INFORMAÇÃO (XIX ENANCIB), v. 24, n. 2, 2018.

CREPALDI, S. A. Contabilidade gerencial: teoria e prática. 6. ed. São Paulo: Atlas, 448 p. 2012.

CREPALDI, S. A. Planejamento tributário: teoria e prática. 2. ed. São Paulo: Saraiva, 2017. 
DA COSTA, W. P. L. B. et al. Utilização da Contabilidade Gerencial nas Micro e Pequenas Empresas. Revista Americana de Empreendedorismo e Inovação, v. 2, n. 2, p. 49-58, 2020.

DUARTE, T. Estrutura e Análise de Balanço. UFMT, Cuiabá, 2015.

FERREIRA, D. et al. Expectativas profissionais dos ingressantes no curso de graduação em ciências contábeis: um estudo em uma instituição de ensino superior. Revista Mineira de Contabilidade, v. 21, n. 1, p. 69-81, 2020.

GITMAN, L. J. Princípios de administração financeira. 12. ed. São Paulo: Pearson Prentice Hall, 2010.

HOJI, M. Administração financeira e orçamentária: matemática financeira aplicada, estratégias financeiras, orçamento empresarial. 12. ed. São Paulo: Atlas, 2017.

IUDICIBUS, S. Análise de balanços. 10. ed. São Paulo: Atlas, 2010.

LACOMBE, F. J. M. Teoria geral da administração. São Paulo: Saraiva, 2009.

LAKATOS, E. M.; MARCONI, M. de A. Fundamentos de Metodologia científica. 7. ed. São Paulo: Atlas, 2010.

LEMES JÚNIOR, A. B.; PISA, B. J. Administrando micro e pequenas empresas. Rio de Janeiro: Campus, 2010.

LIMA, L. J. A.; SOUSA, L. S. A importância das ferramentas contábeis gerenciais para a continuidade e otimização das atividades das micro e pequenas empresas: uma pesquisa de campo na Feira da Oito de Maio em Icoaraci Belém (Pa). Amazônia em Foco, Castanhal, v. 2, n. 3, p. 117-138, jul./dez. 2013.

MACIEL, R. H. et al. Multiplicidade de vínculos de médicos no Estado do Ceará. Revista de Saúde Pública, v. 44, p. 950-956, 2010. 
MARION, J. C. Contabilidade empresarial. 16 ed. São Paulo: Atlas, 2012.

MOREIRA, C. S.; et al. Gerenciamento Tributário das empresas brasileiras: uma análise do regime tributário de transição (Rtt) versus regime tributário definitivo (Rtd). ConTexto, v. 20, n. 46, 2020.

MOREIRA, R. L. et al. A importância da informação contábil no processo de tomada de decisão nas micro e pequenas empresas. Revista Contemporânea de Contabilidade, Florianópolis, v. 10, n. 19, p. 119-140, abr. 2013.

MOTTA, D. S. Planejamento tributário: estudo de caso em uma clínica odontológica a partir da Lei Complementar no 155/2016. 2017.

OLIVEIRA, D. de P. R. de. Sistemas, organização e métodos: uma abordagem gerencial. 21. ed. São Paulo: Atlas, 2013.

OLIVEIRA, G. J. et al. Contabilidade Empresarial. Revista De Trabalhos Acadêmicos-Universo Belo Horizonte, v. 1, n. 2, 2017.

PADOVEZE, C. L. Contabilidade empresarial e societária. IESDE BRASIL SA, 2012.

PEREIRA, W. Uma história da Odontologia no Brasil. Revista História \& Perspectivas, v. 25, n. 47, 2012.

ROSS, S. A.; et al. Fundamentos de administração financeira. 9. ed. Porto Alegre, RS: AMGH Editora, 2010.

RIBEIRO, M. C. et al. Características Empreendedoras dos Profissionais de Contabilidade de Um Município da Amazônia Paraense. Revista Paraense de Contabilidade, v. 4, n. 3, p. 64-77, 2019. 
SANTOS, D. T. dos; VAGO, R. M. A importância do Planejamento Tributário em uma clínica de saúde: um estudo de caso em uma empresa no município de Tomé-Açu/PA. 2019.

SANTOS, J. J. Contabilidade e análise de custos: modelo contábil, Métodos de depreciação, ABC: Custeio Baseado em Atividades, análise atualizada de encargos sociais sobre salários. 5 ed. São Paulo: Atlas, 2009.

SANTOS, J. L.; SCHMIDT, P. Contabilidade Societária. 4. ed. São Paulo: Atlas, 2011.

SANTOS, U. B. et al. O conteúdo das disciplinas tributárias nos cursos de ciências contábeis no Brasil: um estudo sobre a abordagem do simples nacional e lucro presumido. Revista Razão Contábil \& Finanças, v. 12, n. 2, 2021.

SANVICENTE, A. Z.; SANTOS, C. da C. Orçamento na administração de empresas: planejamento e controle. 2. ed. São Paulo: Atlas, 2013.

SILLA, F. L. Fluxo de caixa: instrumento de planejamento, análise e controle. Trabalho de Conclusão de. Instituto Municipal de Ensino Superior de Assis, 2010.

SILVA, J. B.; MIRANDA, J. F. Responsabilidade dos contadores na elaboração e emissão de decores. Humanidades \& Inovação, v. 6, n. 2, p. 300-310, 2019.

SILVA, R. F. et al. A história da Odontologia Legal no Brasil-Parte 2: Origem enquanto disciplina e especialidade. Revista Brasileira de Odontologia Legal, v. 4, n. 3, 2017.

SOUZA, R. A. R.; RIOS, R. P. Contabilidade Gerencial como Ferramenta para Gestão Financeira nas Microempresas: Uma Pesquisa no Município de São Roque-SP. Revista Eletrônica Gestão e Negócios, São Roque, v. 2, n. 1, p. 1-18, 2011. 
STACKE, J. A. Análise da utilização das ferramentas contábeis gerenciais em micro e pequenas empresas. Trabalho de Conclusão de Curso. 2017.

SZUSTER, N. et al. Contabilidade geral: introdução á contabilidade societária. 3. ed. São Paulo: Atlas. 2011.

VERGARA, S. C. Projetos e relatórios de pesquisa em administração. 14. ed. São Paulo: Atlas, 2013.

Enviado: Setembro, 2021.

Aprovado: Outubro, 2021. 